\title{
A Reply to van der Voort's Response to Welch's Review of "Urihi A: A Terra- Floresta Yanomami"
}

Bruce Albert and William Milliken with Gale Goodwin Gomez. São Paulo: Instituto Socioambiental, 2009. 207 pp., illustrations, tables, bibliography, appendices, index. Paperback ISBN: 978-85-85994-72-3.

By James R. Welch ${ }^{1}$

Reviewer Address: ${ }^{1}$ Escola Nacional de Saúde Pública, Fundação Oswaldo Cruz, Rio de Janeiro, welch@ensp.fiocruz.br

Received: January $26^{\text {th }} 2011$

Volume 1:51

Published: February $6^{\text {th }} 2011$

(C) 2010 Society of Ethnobiology

I wish to thank Hein van der Voort for his positive comment regarding the ethnobotanical contents of my review of "Urihi A: A Terra-Floresta Yanomami" (Ethnobiology Letters 2010, 1:18-19). I also would like to affirm that his recent response (Ethnobiology Letters 2010, 1:39) includes other relevant information about the book. In particular, I agree it is useful to mention that this Portuguese language book is an extensively revised and updated edition of a book previously published in English. I appreciate his effort to make that information known.

However, I take issue with his main argument that I failed to mention a third author, Gale Goodwin Gomez. It is factually incorrect to identify Gomez as co-author and unwarranted to suggest that my "oversight" should not be excused. Although the allocation of authorship is a nuanced issue for authors, in this case the authors identified Gomez's contribution as collaboration and not authorship. The distinction is clearly presented on the copyright page of the book, where Bruce Albert and William Milliken are listed as authors and Gomez is listed separately as a collaborator ("colaboração" in Portuguese). As is the case for translation and illustration, it is neither obligatory nor usual to include collaborators in the list of authors in the bibliographical citation of book reviews. This is true even if the collaboration was very important, as I have every reason to believe was the case in this example. 